\title{
Mortar composite based on wet oxidative degraded cellulosic spinney waste fibers
}

\author{
H. M. Saleh • S. B. Eskander • H. M. Fahmy
}

Received: 16 November 2012/Revised: 17 April 2013/Accepted: 1 May 2013/Published online: 25 May 2013

(C) Islamic Azad University (IAU) 2013

\begin{abstract}
Textile industry has become an essential part of modern society, and waste production is an inevitable outcome of the developmental activities. Present paper outlines a direct approach toward a real problem of managing spinney waste fibers generated during textile industry. Simultaneously, shortage in landfill disposal space is another trouble associated with dumping of these hazardous wastes. Direct incorporation of these wastes into cementitious materials faces some disadvantages, so a partial oxidative degradation treatment was performed for those wastes in laboratory-scale experiments. Slurry resulted from the degradation process was incorporated into a mixture of cement/sand as hydrating agent to produce a mortar composite. Mechanical integrity and weight stability of the mortar composite produced were evaluated at the end of setting and hardening period under different variables. Based on the experimental results, the nominated mortar composite could be considered as an added-value product suitable for various applications, for example inert matrix for immobilization of some low and intermediate levels radioactive wastes, decorative tiles, building bricks, light concrete.
\end{abstract}

Keywords Cellulosic spinney waste fibers - Wet oxidation - Immobilization · Cement - Mortar composite . Waste management

\section{Introduction}

Wastes generated during textile manufacturing, in all categories, are generally disposed directly as solid waste in

H. M. Saleh $(\varangle) \cdot$ S. B. Eskander · H. M. Fahmy

Radioisotope Department, Nuclear Research Center,

Atomic Energy Authority, Dokki, Giza 12311, Egypt

e-mail: hosamsaleh70@yahoo.com sanitary landfills or incinerated before disposal. Spinning and weaving by-products are produced yearly all over the world containing a substantial amount of cellulose-based wastes. According to the Cotton Arbitration and Testing General Organization, Egyptian Ministry of Trade and Industry, it has been reported that more than $13 \%$ by weight of raw materials subjected to spinning process are accumulated as solid wastes (Fahmy et al. 2012). In some cases, the average of 14-20\% is lost during combing and yarn production (Frazer 2004). Similar data were reported previously for waste generated from cotton processing (Koutný et al. 2007).

The sanitary backfills will be reduced significantly in the future, thereby increasing the accumulation of these wastes will extensively appear (Eskander and Saleh 2012). Hazardous wastes such as spinney waste fibers may pose a potential hazard to the human health or the environment when improperly treated, stored, transported or disposed off or managed (Misra and Pandey 2005; Mahalakshmi et al. 2011). One of the most harmful effects is the release and accumulation of huge amounts of gases into the repository environment (Eskander et al. 2009). On the other hand, the incorporation of hazardous wastes into cement materials has received great attention and may provide a satisfactory solution for the disposal problem accompanied with other drawbacks such as the biodegradation of the cellulosic content included in the solidified cementitious matrix (Saleh and Eskander 2009; Saleh et al. 2011, 2012; Saleh and Eskander 2012a; Ghattas et al. 2012; Eskander et al. 2012a; Bayoumi et al. 2012). Utilization of these wastes as an additive in cement and/or concrete materials provides several advantages, for example reducing the cost of formed cementitious products due to minimization of cement by employment of spinning and weaving by-products, mitigation of the demand upon a 
limited disposal capacity, minimizing the management expense for all harmful waste categories and giving environmental benefits related to reusing of the disposed hazardous wastes and limitation of the expected hazardous gases emission (Eskander et al. 2009).

Therefore, the management of these wastes as hazards should be taken into account. Wet oxidative degradation technique as a treatment process was performed for the destruction of spinning waste fibers using hydrogen peroxide as an oxidant. The degraded slurry obtained from this process was used to hydrate mortar components (Saleh and Eskander 2012b; Eskander et al. 2012b). The produced solidified matrix of degraded spinney waste slurry and mortar was subjected to different experimental investigations to evaluate its general characterizations. Moreover, this product can be poured into molds to form flat panels, pipes, decorative edging and bricks.

The current study as one of a comprehensive program planned in the Radioisotope Department, Egyptian Atomic Energy Authority, is aiming at the management of hazardous spinney waste fibers. This manuscript concentrates on two laboratory-scale tasks: firstly, the treatment of spinney waste fibers, using wet oxidative degradation technique, aiming at transformation of these wastes to a form suitable for the subsequent incorporation process, and secondly, the incorporation of the resulting partially degraded slurry into mortar. The mechanical strength of tested specimens as well as the weight stability of the finally obtained mortar composite would be evaluated under different experimental conditions.

Date and location of the research

This study was carried out during 2008-2010 and written during 2012. The study was performed at Radioisotope Department, Atomic Energy Authority, Egypt.

\section{Materials and methods}

Materials

Spinney waste

Spinney waste fiber is one of the solid cellulose-based wastes, which is generated during the spinning of cotton raw materials. Cellulose is a natural polymer consisting of long chains of linked sugar molecules (Dorée 1947). The length of non-workable waste fiber used in this study is $<13 \mu \mathrm{m}$. Chemically, this waste is mainly composed of cellulose besides low content of lignin and hemicellulose. The elemental analysis of spinning cellulose-based waste fibers was carried out using Flash-EA1112, and the obtained data are represented in Table 1.
Table 1 Some elements of interest present in dry spinney waste fibers

\begin{tabular}{llll}
\hline Nitrogen $(\%)$ & Hydrogen $(\%)$ & Carbon $(\%)$ & Sulfur $(\%)$ \\
\hline 0.183 & 6.912 & 45.570 & 0.113 \\
\hline
\end{tabular}

Table 2 Chemical composition of the cement used (\%)

\begin{tabular}{llllllll}
\hline $\mathrm{SiO}_{2}$ & $\mathrm{Al}_{2} \mathrm{O}_{3}$ & $\mathrm{Fe}_{2} \mathrm{O}_{3}$ & $\mathrm{CaO}$ & $\mathrm{MgO}$ & $\mathrm{K}_{2} \mathrm{O}$ & $\mathrm{SO}_{3}$ & $\begin{array}{l}\text { Insoluble } \\
\text { residues }\end{array}$ \\
\hline 19.84 & 4.74 & 4.0 & 61.01 & 2.5 & 0.6 & 2.4 & 0.95 \\
\hline
\end{tabular}

Lime saturation factor $=97 \%$ by weight, loss on ignition $=3.5 \%$

\section{Cement materials}

The cement used in the present study is the locally manufactured Portland cement (PC). This cement was manufactured according to Egyptian Standard Specifications ES 4756-1/2005 (Egyptian Standard Specifications 2005), having the chemical analysis presented in Table 2.

Experimental approaches

\section{Treatment of spinney waste fibers}

The treatment process was carried out at atmospheric pressure and at $100{ }^{\circ} \mathrm{C}$ in the presence or absence of a catalyst.

Before starting the degradation process, a predetermined weight of spinning waste fibers was saturated with distilled water at the weight ratio of 1:25. The wetted waste fibers was introduced into a rounded bottom flask and allowed to stabilize at $100{ }^{\circ} \mathrm{C}$ before adding the oxidant, commercial $35 \% \mathrm{H}_{2} \mathrm{O}_{2}$, to the system at a definite rate of $1 \mathrm{ml} / \mathrm{min}$. The addition of oxidant was under the surface of the mixture with continuous stirring of slurry to insure the complete consumption of oxidant added. For studying the effect of catalyst on the degradation process, $\mathrm{FeSO}_{4} \cdot 7 \mathrm{H}_{2} \mathrm{O}$ was added at a predetermined weight with wetted spinning waste before adding hydrogen peroxide. At the end of the reaction, the degraded slurry was left to cool, filtered and then the weight of solid residues was determined.

The data obtained from the degradation processes were represented either in weight reduction or in degradation percentages, to allow for comparison of these data with those given in the literatures.

$$
\begin{aligned}
& \text { Weight reduction }(\%) \\
& =\frac{(\text { Weight of solid }- \text { Weight of residue })}{\text { Weight of solid }} \times 100
\end{aligned}
$$

Degradation (\%)

$$
=\frac{(\text { Carbon content added }- \text { Carbon remaining })}{\text { Carbon content added }} \times 100
$$


where weight of solid is the net weight of the waste fiber added in grams, weight of residue is the net weight of the solid residues remaining after filtrating and drying the degraded slurry in grams, carbon content added is the carbon content in the waste fibers subjected to degradation, and carbon remaining is that carbon in the remained slurry after degradation process in grams.

The produced slurry was mixed with cement powder and sand at various ratios to yield hard cementitious product that can be used in different applications.

\section{Formulation of the cementitious product}

This work was conducted with mortar specimens having different mortar compositions prepared by mixing cement powder with increasing volumes of degraded fibers slurry. The elemental analysis of the degraded fibers slurry is represented in Table 3.

Mortar cylindrical blocks were prepared by different cement/sand ratios with or without varying the volume of slurry resulting from the degradation of spinning wastes. The prepared mortar paste was poured into 3-5 cylindrical plastic molds of $60 \pm 2.0 \mathrm{~mm}$ height and $31 \pm 0.5 \mathrm{~mm}$ diameter for each test composition. This paste was compacted manually for fixed time and then tightly closed with plastic covers. The specimens were made and cured for setting and hardening in laboratory environment of temperature $25 \pm 5{ }^{\circ} \mathrm{C}$ under their humid conditions for 28 days, according to procedures described for standard cured specimens in ASTM C31 (ASTM 2000a). The changes in weight loss of the specimens were recorded during the curing period. At the end of curing period, the hardened cementitious blocks of the degraded slurry were demolded and subjected to evaluate the mechanical integrity by measuring the compressive strength in accordance with ASTM C39 (ASTM 2000b) using MaTest, E 159 SP apparatus.

Fourier Transform Infrared spectrophotometer (FTIR8201PC, Shimadzu) was used to investigate the spinney waste fibers, as well as solid residue and slurry resulted from the oxidation degradation process.

The solidified cementitious product was grounded, and thermal measurements were performed for the powder using aluminum oxide as a reference material. TGA and DTA analyses were carried out using TGA and DTA-50H Shimadzu apparatus at heating rate $10{ }^{\circ} \mathrm{C} / \mathrm{min}$ in nitrogen atmosphere over a temperature range from ambient

Table 3 Characteristics of residual degraded slurry

\begin{tabular}{llll}
\hline $\mathrm{pH}$ & Total solid residue $(\%)$ & Carbon $(\%)$ & Hydrogen $(\%)$ \\
\hline 6.9 & 1.1 & 39.6 & 5.7 \\
\hline
\end{tabular}

temperature to $1,000{ }^{\circ} \mathrm{C}$. Endothermic and exothermic reactions as well as the mass-loss of the powdered solid blocks were measured as a function of temperature.

Theoretical background

\section{Treatment of spinney waste fibers}

Wet oxidative degradation technique (Ghattas and Eskander 1991; Saleh 2012) was chosen for its numerous advantages as a treatment process for the degradation of the spinning waste fibers before their incorporation into cementitious materials. Through this step, the spinney waste fibers were degraded to a form that can be easily used for the cement reinforcement. That technique is based on the degradative action of hydrogen peroxide on organic moiety of spinney waste fibers. The system proceeds at atmospheric pressure and at $100{ }^{\circ} \mathrm{C}$ in presence or absence of a catalyst. The treatment outcome slurry was mixed with cement powder and sand at various ratios to yield hard cementitious product that can be used in different daily applications after their evaluation.

\section{Degradation of spinney waste fibers by hydrogen peroxide}

Hydrogen peroxide plays the key role in the degradation transaction of the spinney waste fibers. Decomposition of the $\mathrm{H}_{2} \mathrm{O}_{2}$ is supposed to take place through the following reaction steps:

$$
\begin{aligned}
& \mathrm{H}_{2} \mathrm{O}_{2} \rightarrow \mathrm{H}_{2} \mathrm{O}+\mathrm{O} \\
& \mathrm{O}+\mathrm{O} \rightarrow \mathrm{O}_{2}
\end{aligned}
$$

The combination of oxygen atoms is extremely rapid reaction, and the observed rate of this reaction is corresponded to the unimolecular reaction which takes place in the first step, and proceeds more slowly (Bahl et al. 2004). Hydrogen peroxide bond $(-\mathrm{O}-\mathrm{O})$ in which at least one oxygen atom is active leads to the production of molecular oxygen that has been correlated with the partial oxidation of the degraded spinney waste fibers (Vigo 1994). Low-temperature wet degradation process takes the advantages of high reactive radicals such as $\mathrm{HO}^{-}$and $\mathrm{O}^{-}$ generated from the decomposition of the hydrogen peroxide oxidant. This decomposition can also take place through metal ion catalysis (Wu et al. 1994). Ferrous sulfate salt $\left(\mathrm{FeSO}_{4} \cdot 7 \mathrm{H}_{2} \mathrm{O}\right)$ was used as a catalyst to enhance the degradation action of hydrogen peroxide and consequently processing the waste fibers. When hydrogen peroxide added to a reaction vessel contains the boiled wetted spinney waste fibers and ferrous sulfate, the following reactions supposed to take place (Haber and Weiss 1935).

$\mathrm{Fe}^{+2}+\mathrm{H}_{2} \mathrm{O}_{2} \rightarrow \mathrm{Fe}^{+3}+\mathrm{OH}+\mathrm{HO}^{-}$ 
As refer to Fenton reactions (Wu et al. 1994), the coming chain reactions could be postulated.

$$
\begin{aligned}
& \mathrm{HO}+\mathrm{H}_{2} \mathrm{O}_{2} \rightarrow \mathrm{H}_{2} \mathrm{O}+\mathrm{HOO} \\
& \mathrm{HOO}+\mathrm{H}_{2} \mathrm{O}_{2} \rightarrow \mathrm{O}_{2}+\mathrm{H}_{2} \mathrm{O}+\mathrm{HO}^{-} \\
& \mathrm{HO}+\mathrm{Fe}^{+2} \rightarrow \mathrm{Fe}^{+3}+{ }^{-} \mathrm{OH} \\
& \mathrm{Fe}^{+3}+\mathrm{H}_{2} \mathrm{O}_{2} \rightarrow \mathrm{Fe}^{+2}+\mathrm{HOO}^{-}+\mathrm{H}^{+} \\
& \mathrm{Fe}^{+3}+\mathrm{HOO}^{-} \rightarrow \mathrm{Fe}^{+2}+\mathrm{O}_{2}+\mathrm{H}^{+}
\end{aligned}
$$

High reactive hydroxyl radicals react with the organic moieties of the spinning fibers either by subtract ions of hydrogen or by addition to the unsaturated site to yield organic radical which are readily oxidized by $\mathrm{O}_{2}$ (Nonhebel and Walton 1974).

$\mathrm{RH}+\mathrm{HO} \rightarrow \mathrm{H}_{2} \mathrm{O}+\mathrm{R}$.

$$
\begin{aligned}
& \mathrm{R}-\mathrm{C}=\mathrm{C}+\mathrm{HO} \rightarrow \mathrm{R}-\mathrm{C}-\mathrm{C}-\mathrm{OH} \\
& \stackrel{\mathrm{I}}{\mathrm{I}}+\mathrm{O}_{2} \rightarrow \mathrm{RCOO} \\
& \mathrm{RCOO} \rightarrow \mathrm{R}+\mathrm{CO}_{2}
\end{aligned}
$$

Therefore, the end product of the degradation process seems to be degraded fibers, $\mathrm{CO}_{2}$ and $\mathrm{H}_{2} \mathrm{O}$.

\section{Results and discussion}

FT-IR investigation of spinney waste fibers before and after treatment

To confirm the previous postulations, FT-IR analysis as a non-destructive technique was carried out for the untreated waste fibers as well as for the solid residues and the secondary waste slurry resulted from the batch-wise laboratory-scale destruction process.

IR spectrum of undegraded spinney waste fibers (Fig. 1a) shows an extremely intensive $\mathrm{O}-\mathrm{H}$ stretching frequency centered near $3,375 \mathrm{~cm}^{-1}$ due to the broad band spreads from $\approx 3,700$ to approximately $3,000 \mathrm{~cm}^{-1}$. This band is due to free and/or bonded $\mathrm{OH}$ groups.

Part of the absorption in this region may be due to the water of the sample. Band near $2,918 \mathrm{~cm}^{-1}$ may be due to the stretching vibration of $-\mathrm{CH}$ group, while the stretching mode of the aldehydic $\mathrm{C}=\mathrm{O}$ groups in the cellulosic fibers appears near $1,659 \mathrm{~cm}^{-1}$. The band detected around $1,430 \mathrm{~cm}^{-1}$ may be due to $\mathrm{CH}_{2}$ scissors motion in the cellulose macromolecules, while the band absorbed near $1,320 \mathrm{~cm}^{-1}$ is due to the $\mathrm{O}=\mathrm{C}-\mathrm{O}$ groups stretching frequency. The band came approaching $1,160 \mathrm{~cm}^{-1}$ has been interpreted as asymmetric $\mathrm{C}-\mathrm{O}-\mathrm{C}$ etheric bridge stretching
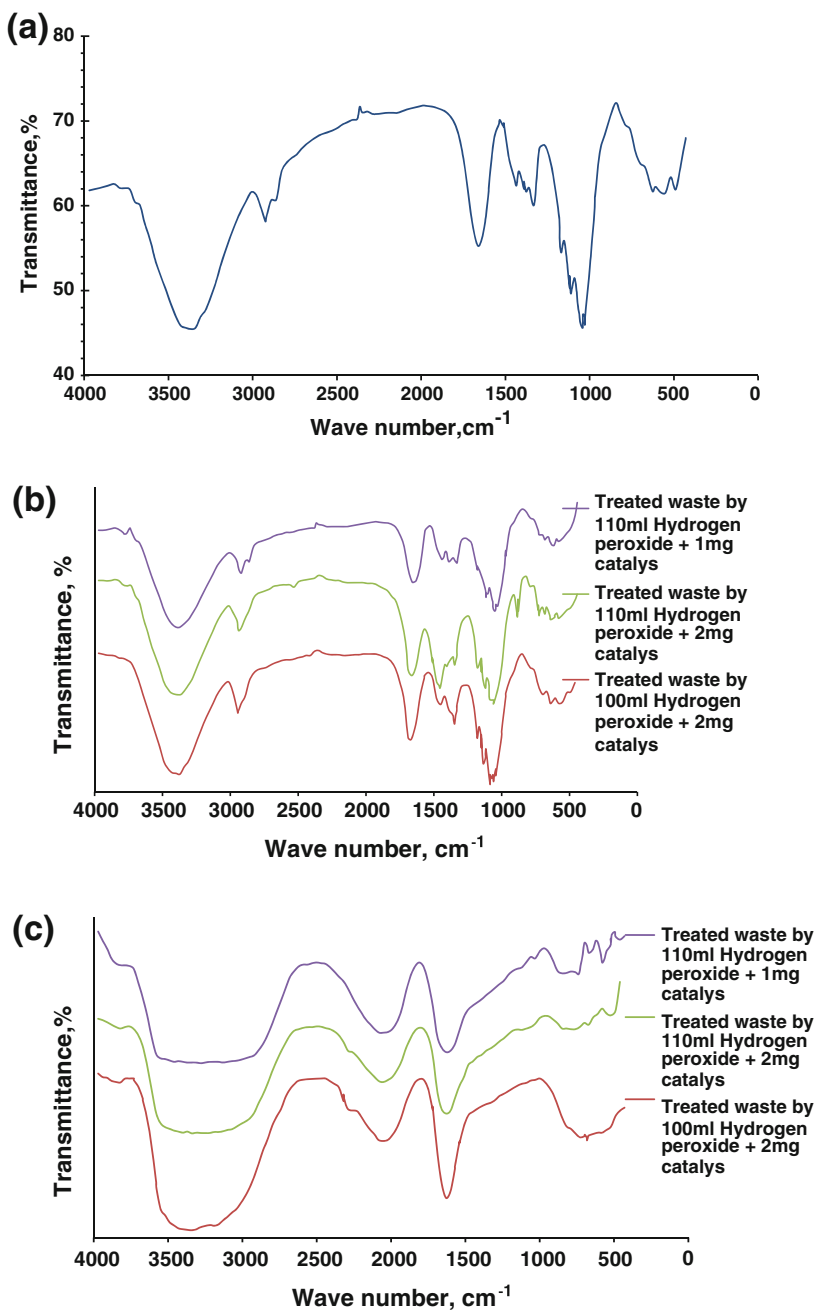

Fig. 1 FT-IR spectra of characteristic bands of a spinney waste fibers, b solid resides resulted from degradation process of the spinning waste fibers using different volumes of $\mathrm{H}_{2} \mathrm{O}_{2}$ and/or various catalyst contents, c slurry resulted from degradation process of the waste fibers using different volumes of $\mathrm{H}_{2} \mathrm{O}_{2}$ and/or various catalyst contents

vibration mode, while that at about $1,110 \mathrm{~cm}^{-1}$ is due to $\mathrm{C}-\mathrm{O}$ groups deformation (Fig. 1a). Similar bands assignments for cellulosic materials were obtained in the previously published studies (Schuchardt et al. 1995; Henniker 1967).

FT-IR spectra of the solid residue obtained from batchwise degradation process using different amounts of hydrogen peroxide and those in presence or absence of $\mathrm{FeSO}_{4} \cdot 7 \mathrm{H}_{2} \mathrm{O}$ as a catalyst are represented in Fig. 1b. It is obviously stated from the obtained spectrograms that the band assignments for all spectra are nearly identical and similar to that of undegraded waste cellulosic fibers in Fig. 1a. This favors an endwise homiletic scissor mechanism of the degradation process. Due to this mechanism, hydrogen peroxide degrades firstly the solid matrix then oxidizes the degraded moiety (Eskander and Saleh 1999). 
On the other hand, the spectra of the solution resulted from the filtration of the degraded mixture obtained from the batch-wise experiments are shown in Fig. 1c.

The most predominate bands present in all of these spectra are those due to the stretching vibration of $\mathrm{O}-\mathrm{H}$ groups of water and appear as a broad band near to $3,530-3,240 \mathrm{~cm}^{-1}$. Otherwise, bands approach $1,640 \mathrm{~cm}^{-1}$ may be attributed to -O-H deformation (Henniker 1967).

Clearly, from the previous discussion, the main aim of the treatment step of spinney cellulosic waste fibers is to convert them to a form that can be adequately incorporated into cementitious materials and terminated in a homogenous composite having acceptable physical and mechanical characterizations. Batch-wise treatment experiments were conducted to optimize the time and the amount of hydrogen peroxide required for the degradation of a predetermined weight of a spinney waste fibers that based on visual inspection of the reaction vessel.

Theoretically, the degradation process started at the moment of adding hydrogen peroxide to the hot wetted spinney waste fibers. At a definite point, the degraded waste fibers is converted to a thickly combination (nearly at the addition of $\approx 800 \mathrm{ml} \mathrm{O}_{2} / \mathrm{g}$ spinney waste fibers), then the reaction mixture starts to dissolute. This behavior may be referred to the change in reaction medium from the degradation point (thick form) to starts the oxidation step with continual addition of hydrogen peroxide. Since we are looking after the degradation of the waste fibers and not for their complete oxidation, $\mathrm{H}_{2} \mathrm{O}_{2}$ addition was stopped at that point of dissolution. Thereby, the variation in weight reduction and the degradation percentages as a function of oxidant addition were followed, and the data obtained are represented in Table 4.

Both degradation factor (based on the carbon added included the solid fiber) and weight reduction percentages were increased by increasing the volume of oxygen added in the form of hydrogen peroxide. This was attributed to the degradative action of $\mathrm{H}_{2} \mathrm{O}_{2}$ on the cellulosic waste fibers. Also, increasing the concentration of $\mathrm{FeSO}_{4} \cdot 7 \mathrm{H}_{2} \mathrm{O}$ catalyst, keeping the volume of $\mathrm{O}_{2}$ added constant was

Table 4 Weight reduction and degradation percentages of spinney waste fibers as a function of $\mathrm{H}_{2} \mathrm{O}_{2}$ added

\begin{tabular}{llllll}
\hline Dry waste added $(\mathrm{g})$ & 10 & & & & \\
Carbon content in waste $(\mathrm{g})$ & 4.557 & & & & \\
$\mathrm{H}_{2} \mathrm{O}_{2}$ added (ml/g waste) & 8.5 & 9.5 & 11.3 & 12.3 & 12.3 \\
$\mathrm{H}_{2} \mathrm{O}_{2}$ added (ml/g carbon) & 18.3 & 20.4 & 24.4 & 26.5 & 26.5 \\
Catalyst/waste (mg/g) & 0 & 2 & 2 & 2 & 1 \\
Remained residue (g) & 5.28 & 4.75 & 4.21 & 3.6 & 4.03 \\
Carbon content in residue (g) & 1.99 & 1.88 & 1.37 & 1.32 & 1.40 \\
Weight reduction (\%) & 47 & 57 & 58 & 64 & 60 \\
Degradation (\%) & 56 & 59 & 70 & 71 & 69 \\
\hline
\end{tabular}

accompanied with a slight increase in the degradation rate $(<2 \%)$ but with a detectable increase in the weight reduction percentage (more than $4 \%$ ), Table 4 . This may confirm that the point chosen to stop the addition of $\mathrm{H}_{2} \mathrm{O}_{2}$ could be nearly the optimal point to describe the change from degradation to the oxidation steps.

Based on the data reported in Table 4, the volume of $\mathrm{O}_{2}$ at $800 \mathrm{ml}$ and $2 \mathrm{mg}$ catalyst per $1 \mathrm{~g}$ spinney waste fibers were chosen for the batch-wise degradation experiment, where after this conditions, slight improvement in both weight reduction and degradation percentages are achieved. All the treatment processes of the spinney waste fibers were performed at that stated figures, or otherwise conditions will be indicated. The degraded slurry derived from the treatment process was incorporated into mortar material (Fahmy et al. 2012).

Incorporation of degraded wastes into mortar material

There is a continuous worldwide trend toward using a lightweight concrete (e.g. mortar) in various applications such as high-rise building and shell roofs (Gani 1997). In this part of study, the feasibility of incorporating the degraded spinney waste fibers into a mortar material will be investigated and its properties as one of lightweight concrete will be evaluated.

Mechanical integrity as a function of slurry/cement ratio

In mortar composition, by increasing the water/cement ratio, an increase in the compressive strength values up to the concentration 0.7 was obtained. This could be explained as, at low w/c ratios, incomplete reaction of cement with water is the probably main reason for the low mechanical integrity which due to the deficiency of water required for hydration. On the other hand, at w/c ratio $>0.7$, some unreacted water remains in excess than that required for hydration and the volume occupied by these excess water results in the formation of more capillary pores during the setting of mortar and consequently in the reduction of the compressive strength values (Fig. 2). Replacing the water by waste slurry, as end product from the degradation process, to hydrate the mortar was carried out to form solid mortar composite blocks that subject to mechanical integrity evaluation. The data of compressive strength values of the mortar composite blocks having increasing percentages of the slurry exhibited acceptable mechanical strength values (Fig. 2).

It is worth mentioning that, at slurry/cement ratio of 0.7 , the highest compressive strength value was obtained in agreement with that result obtained from mortar materials hydrated by water. In addition, at the slurry/cement ratio of 


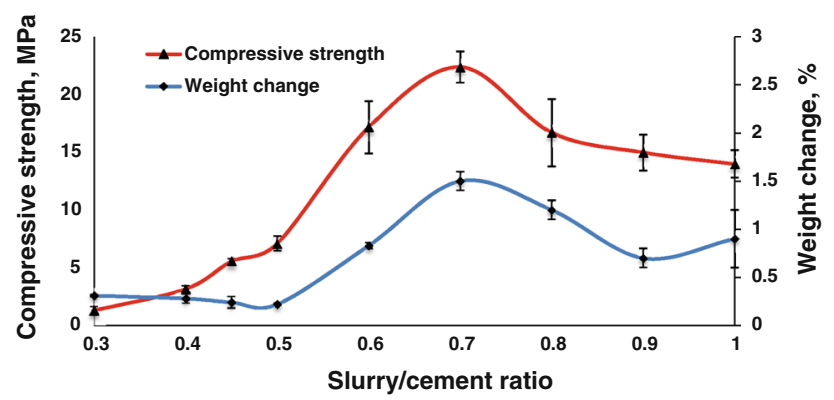

Fig. 2 Compressive strength and weight stability of mortar composite containing increasing percentage of slurry of degraded spinney waste fibers

1.0 , the compressive strength value reduced to $\approx 14 \mathrm{MPa}$. However, even at the equivalent ratio of slurry/cement, the compressive strength value is highly compared to that suggested in the literatures as the acceptable values (i.e. 350-3,500 kpa) (Neville and Brooks 2010) and also that recommended by The Egyptian Standard Specifications (Egyptian Standard Specification for Portable Walls 2005). Clearly, from Fig. 2, the values of the mass changes during the setting and hardening period (i.e. 28 days) were generally small. Therefore, incorporating the slurry generated from the degradation of spinney waste fibers has no effect on the physical integrity of the mortar composite blocks which considered as a valuable advantage in incorporating the treated than the untreated spinney waste fibers (Fahmy et al. 2012).

\section{Mechanical integrity as a function of cement/sand ratio}

The sand content in mortar composite could be evaluated to study its effect on the physical stability of the final hard product. Set of specimens were prepared with increasing amounts of sand, this set was obtained by using a slurry obtained from the degradation process as hydrating agent for sand and cement. The data obtained from the weight change and the compressive strength measurements after curing time of 28 days are illustrated in Fig. 3. The variation in mass-loss due to the setting and hydration is highly matched to the control set. This confirms again that the incorporation of the degraded spinney fibers did not affect the physical durability of the final mortar product. In addition, it should be spotted that the results from the mechanical integrity of the two experimental and control sets were displayed similar tendency, where increasing the $c / s$ ratio was accompanied by increase in the compressive strength values up to the top at ratio $1 / 3$. Behind this ratio, the mechanical integrity of the mortar product was decreased manifestly (Fig. 3). However, it should be stated that bleeding took place for the low $\mathrm{c} / \mathrm{s}$ ratios (i.e. at the ratios $1 / 1$ and $1 / 2$ ) for both the experimental and control groups.

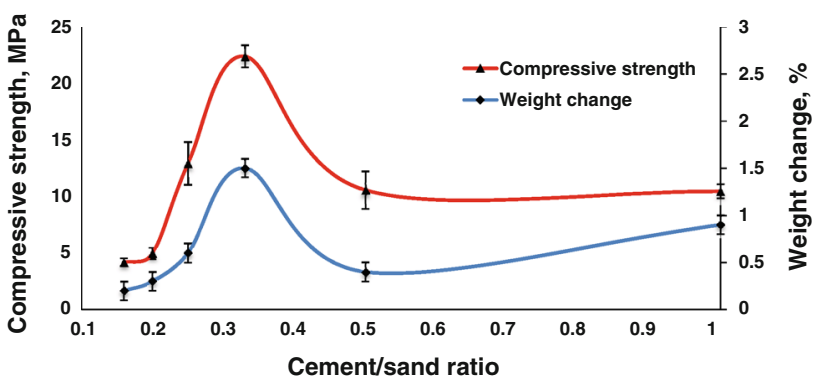

Fig. 3 Compressive strength and weight stability of mortar composite containing increasing contents of sand

Table 5 Behavior of mortar composite during thermogravimetry (TGA) and mass-loss as a function of temperature

\begin{tabular}{ll}
\hline Temperature range $\left({ }^{\circ} \mathrm{C}\right)$ & Mass-loss $(\%)$ \\
\hline $27-112.7$ & 0.873 \\
$112.7-352.3$ & 1.992 \\
$352.3-552.3$ & 1.070 \\
$552.3-854.3$ & 2.894 \\
Above 850 & 6.808 \\
\hline
\end{tabular}

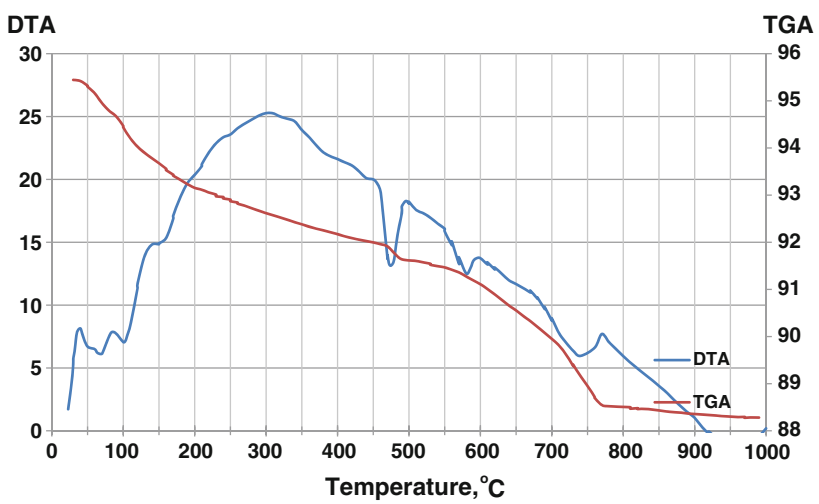

Fig. 4 Thermogravimetric analysis and differential thermal analysis of mortar composite

Thermal stability of slurry-mortar composite

In order to assess thermal stability of the mortar composite blocks, thermogravimetry (TGA) and differential thermal analyses (DTA) were performed to the nominated composite. TGA measures the mass changes in the samples as a function of temperature, while the DTA evaluates the variations of energy, represented by endothermic or exothermic peaks in the thermograms.

Table 5 and Fig. 4 describe the behavior of the mortar composite under the thermogravimetric analysis (TGA).

Based on the data obtained from the thermal analyses, it could be denoted that TGA curve is characterized by four zones as following: 
Fig. 5 Construction models of the degraded spinney wastemortar composite
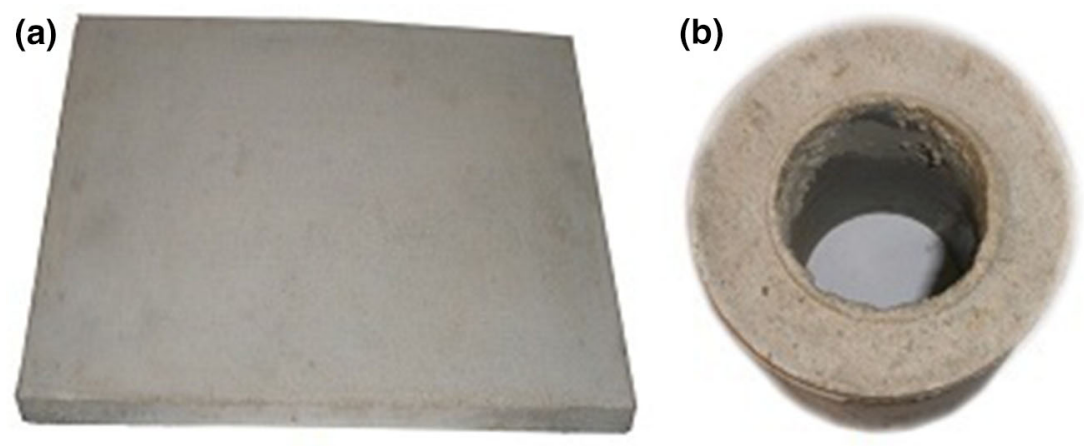

(c)

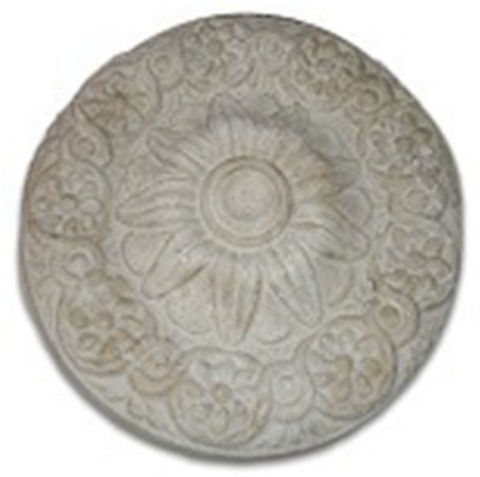

(d)

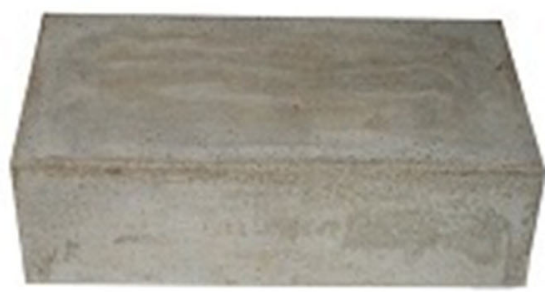

1. Mass-loss at temperature $<120{ }^{\circ} \mathrm{C}$ (i.e. approximately from room temperature up to nearly $113{ }^{\circ} \mathrm{C}$ ) is due to the dehydration of water in pores and release of hydroscopic water. The mass-loss did not exceed $0.9 \%$.

2. The loss in mass at the range of $113-353{ }^{\circ} \mathrm{C}$ is related to the dehydration of water associated with calcium silicate hydrates, ettringite and gypsum.

3. In temperature region of $353-553{ }^{\circ} \mathrm{C}$, a slight massloss was described by the dehydroxylation process [decomposition of portlandite $\mathrm{Ca}(\mathrm{OH})_{2}$ ]. The abundance of $\mathrm{Ca}(\mathrm{OH})_{2}$ could be deduced by TGA curve at $353-553{ }^{\circ} \mathrm{C}$ (the corresponding TGA peak) by considering the following decomposition reaction:

$$
\mathrm{Ca}(\mathrm{OH})_{2(\mathrm{~s})} \rightarrow \mathrm{CaO}_{(\mathrm{s})}+\mathrm{H}_{2} \mathrm{O}_{(\mathrm{g})}
$$

4. The fourth characterizing zone in TGA curve started approximately at $553{ }^{\circ} \mathrm{C}$ up to $853{ }^{\circ} \mathrm{C}$ and attributed to the decarbonation of calcite $\left(\mathrm{CaCO}_{3}\right)$ according to the following reaction:

$$
\mathrm{CaCO}_{3(\mathrm{~s})} \rightarrow \mathrm{CaO}_{(\mathrm{s})}+\mathrm{CO}_{2(\mathrm{~g})}
$$

This may also clarify the noticed increase in the pore water loss according to this reaction.

These results predict the thermal stability of the mortar composite blocks under heating conditions up to more than $800{ }^{\circ} \mathrm{C}$. By correlating the data from TGA to that of DTA thermographs, it could deduce a number of characteristic endothermic peaks as following:
- As endothermic peak up to $\approx 160{ }^{\circ} \mathrm{C}$ which usually conducts to the presence of hydration products, for example $\mathrm{C}-\mathrm{S}-\mathrm{H}$, ettringite...

- Two main characteristic peaks for the cementitious product: The first occurs at $\approx 475{ }^{\circ} \mathrm{C}$ and represents the loss of hydroxyl and hydrogen atoms in the form of water from calcium hydroxide molecules $\mathrm{Ca}(\mathrm{OH})_{2}$, while the second peak is centered near $750{ }^{\circ} \mathrm{C}$ and represents the loss of carbonate ions in the form of carbon dioxide from calcium carbonate molecules $\left(\mathrm{CaCO}_{3}\right)$.

- Endothermic peak near $850{ }^{\circ} \mathrm{C}$ which may correspond to the presence of silica of sand added to the mortar composite matrix.

Collectively and based on the thermal analysis results obtained, it could be concluded that the proposed mortar composite is thermally stable.

Using mortar composite in construction applications

The advantages of the mortar-slurry composite product including durability, light weight and the capacity of providing certain performance characteristics for specific circumstances can be obviously confirmed. The composite product can be poured into molds to form flat panels, pipes, decorative edging and bricks as illustrated, respectively, in Fig. 5a-d. Therefore, the mortar composite could be properly candidate for using as structural sheathing, flooring, roofing and decoration material in residential and other construction projects. 


\section{Conclusion}

Even though the reward gained by the environment through the management, one of the problematic wastes (i.e. spinney wastes) worths the cost paid and may be less than the tipping fees for their landfills. The slurry-mortar composite obtained from hydrating the sand-cement mixture with the degraded spinney waste fibers can be considered as an added-value product due to its acceptable mechanical, physical and thermal stabilities. This product can be applied as inert matrix for solidification of radioactive wastes, building bricks and decorative tiles in addition as light concrete. It is recommended to scale up both wet degradation treatment and the production of the mortar composites for various industrial applicability.

Acknowledgments The authors express their gratitude to the anonymous referees and editors for their constructive comments on earlier drafts of this article.

\section{References}

ASTM (2000a) Standard method of making and curing concrete test specimens in the field (ASTM C31), vol 04.02. Annual Book of ASTM Standards, ASTM, Philadelphia, p 5-10.6

ASTM (2000b) Standard test method for compressive strength of cylindrical concrete specimens (ASTM C39), vol 04.02. Annual Book of ASTM Standards (ASTM), Philadelphia, pp 24-29

Bahl BS, Tuli GD, Bahl A (2004) A essential of physical chemistry, 24th edn. S. Chand \& Company Ltd., New Delhi

Bayoumi TA, Reda SM, Saleh HM (2012) Assessment study for multi-barrier system used in radioactive borate waste isolation based on Monte Carlo simulations. Appl Radiat Isot 70(1): 99-102

Dorée C (1947) The methods of cellulose chemistry. Chapman \& Hall Ltd., London

Egyptian Standard Specification for Portable Walls (1292-2/2005)

Egyptian Standard Specifications (2005) Ordinary Portland cement (OPC) CEM1 (42.5N) Egypt. ES 4756-1/2005

Eskander SB, Saleh HM (1999) Wet oxidative degradation of cellulosic wastes, vol 3: decomposition of tissue paper. In: Proceedings of the 7th international conference on radioactive waste management and environmental remediation (ICEM '99), Nagoya. American Society of Mechanical Engineers, New York

Eskander SB, Saleh HM (2012) Cement mortar-degraded spinney waste composite as a matrix for immobilizing some low and intermediate level radioactive wastes: consistency under frost attack. J Nucl Mater 420(1-3):491-496

Eskander SB, Saleh HM, Fahmy HM (2009) Incorporation of the spinning wastes in cement and mortars. J Radiat Res Appl Sci 2(1):119-136

Eskander SB, Bayoumi TA, Fahmy HM (2012a) Mortar-degraded spinney waste fiber composite for radioactive waste immobilization purposes: efficiency under immersion conditions. Int $\mathrm{J}$ Chem Environ Eng Syst 3(3):1-13

Eskander SB, Bayoumi TA, Saleh HM (2012b) Performance of aged cement-polymer composite immobilizing borate waste simulates during flooding scenarios. J Nucl Mater 420(1-3):175-181
Fahmy HM, Eskander SB, Saleh HM (2012) Applications of recycled textile wastes in cement composite: mortar-spinney wastes composite. LAP Lambert Academic, Germany. ISBN 978-3-659-23099-8

Frazer L (2004) New spin on an old fiber. Environ Health Perspect 112(13):A754-A757

Gani MSJ (1997) Cement and concrete, 1st edn. Chapman \& Hall, London, p 140

Ghattas NK, Eskander SB (1991) Oxidative degradation of spent ion exchange resins and Alpha bearing wastes in aqueous medium, vol 2. In: Proceedings of the international conference on RECOD '91, Sendai. French Nuclear Energy Society, Paris, pp 664-671

Ghattas NK, Eskander SB, Bayoumi TA, Saleh HM (2012) Cementpolymer composite containers for radioactive wastes disposal. Int J Chem Environ Eng Syst 3(2):17-25

Haber F, Weiss J (1935) The catalytic decomposition of hydrogen peroxide by iron salts. Proc R Soc Lond Ser A147

Henniker JC (1967) Infrared spectroscopy of industrial polymers. Academic Press, New York

Koutný R, Čechová B, Hutla P, Jevič P (2007) Properties of heat briquettes on basis of cotton processing waste. Res Agr Eng 53(2):39-46

Mahalakshmi M, Angayarkanni J, Rajendran R, Rajesh R (2011) Bioconversion of cotton waste from textile mills to bioethanol by microbial saccharification and fermentation. Ann Biol Res 2(3):380-388

Misra V, Pandey SD (2005) Hazardous waste, impact on health and environment for development of better waste management strategies in future in India. Environ Int 31(3):417-431

Neville AM, Brooks JJ (2010) Concrete technology, 2nd edn. Prentice-Hall, NJ. ISBN 9780273732198

Nonhebel DC, Walton JC (1974) Free-radical chemistry: structure and mechanism. Cambridge University Press, Cambridge. ISBN 0-521-20149-7

Saleh HM (2012) Treatment and solidification of hazardous organic wastes: radioactive cellulose-based wastes. LAP Lambert Academic, Germany. ISBN 978-3-659-18564-9

Saleh HM, Eskander SB (2009) Long-term effect on the solidified degraded cellulose-based waste slurry in cement matrix. Acta Mont Slovaca 14(4):291-297

Saleh HM, Eskander SB (2012a) Using Portland cement for Encapsulation of Epipremnum aureum generated from phytoremediation process of liquid radioactive wastes. Int $\mathrm{J}$ Chem Environ Eng Syst 3(2):1-8

Saleh HM, Eskander SB (2012b) Characterizations of mortardegraded spinney waste composite nominated as solidifying agent for radwastes due to immersion processes. J Nucl Mater 430(1-3):106-113

Saleh HM, Tawfik ME, Bayoumi TA (2011) Chemical stability of seven years aged cement-PET composite waste form containing radioactive borate waste simulates. J Nucl Mater 411(1-3):185192

Saleh HM, Bayoumi TA, Shatta HA (2012) Mechanical and chemical characterizations of polyester modified cement immobilizing nuclear wastes. Adv Chem Sci 1(1):12-17

Schuchardt U, Bianchi ML, Gonçalves AR, Curvelo AAS, Biscolla FC, Peres LO (1995) Piassava fibers (Attalea funifera): I. Chemical analysis, extraction and reactivity of its lignin. Cell Chem Technol 29(6):705-712

Vigo TL (1994) Textile processing and properties. Elsevier Science, Amsterdam

Wu T, Yun G, Wu J, Yie Y (1994) A study on the wet chemical oxidation and solidification of radioactive spent ion exchange resins. IAEA-TECDOC 851:249-254 